\begin{tabular}{c} 
International Journal of Engineering \& Technology, $7(3.19)(2018) 129-135$ \\
International Journal of Engineering \& Technology \\
SPC \\
Website: $\frac{\text { www.sciencepubco.com/index.php/IJET }}{\text { Research paper }}$ \\
\hline
\end{tabular}

\title{
The Effect of Using Some Google Educational Applications in Teaching Computer Curriculum on the Achievement of Students for the First Year in College of Education, University of Samarra.
}

\author{
Inst. Abdul Munem. Hasan . Ahmed. Ali \\ Department Biology, College Of Education, University Of Samarra \\ *Corresponding author E-mail:abdalmonem424@gmail.com
}

\begin{abstract}
The objective of this research is to find out the effect of the use of some Google educational applications in the process of teaching the computer curriculum on the achievement of students of the first year in college of Education / University of Samarra. The researcher used the semi-experimental method. The sample consisted of (38) male and female students The first year in the Department of biology at the college of Education, Samarra University, was divided into two groups, one experimental, consisting of (19) students and was studied using some Google educational applications through integrated education. The control group consisted of (19). I studied using the traditional method of curing Which is (the lecture method), note that the two groups (experimental and control) equal in number and unequal in the number of variables that could affect the safety of the design follicular Search, the researcher chose a number of topics related to the curriculum of the computer curriculum, which is taught to students of the first year in the college of Education, University of Samarra. These topics are (computer components, electronic penetration, computer virus, operating system). The teaching of objectives for each of these subjects was determined in light of the objectives of the researcher that used a set of research tools. it included (50) questionnaires, including (25 questions of the type of correctness and errors), ( 25 questions of multiple choice type), and the researcher used some Google educational applications in teaching group students (Google Gmail, Google Docs, Google sites, Google+, Google calendar), as well as a web site that includes curriculum materials for the computer curriculum. The researcher used a set of statistical methods including: arithmetic mean, standard deviation coefficient, T-Test) for independent samples, and the research reached the following results:

There are statistically significant differences at the level of significance $(0.05)$ between the mean scores of the experimental group and the scores of the control group students in the post-achievement test for the experimental group studied using some Google educational applications.

In light of the findings of the current research, the researcher recommended a number of recommendations, including the need to use Google's educational applications in teaching computer curriculum in the colleges of education and need to provide Internet service in computer laboratories in universities.
\end{abstract}

Key words: Google Apps for Education, (Teaching), Academic Achievement).

\section{Introduction}

That the use of E-learning methods in universities and educational institutions has become an important requirement of the need for qualitative development of curricula, educational curricula and modern methods of teaching, as e-learning allows the student to learn more and depth according to its abilities, taking into account individual differences of students in the speed of learning, It helps teachers to follow up on their students and then to evaluate them directly, thus helping students develop their abilities and then build their personalities so that they become participants and producers of knowledge, not just recipients.

Google is one of the most important companies in the educational applications and uses a large number of students of universities and schools around the world Google educational applications and through the view of some numbers, we note that in the year (2014) during the month of September only used about 30 million people Google educational applications, In addition, about 190 million people have used Google Drive. There are also about 72 universities that are among the top 100 universities in the United States that use Google Apps in their educational institutions. As for the famous You Tube site, There are more than (400) universities around the world working to record their lectures and i lifted it on this site are either full courses or in part (Yeung, 2012).

(Mustafa, 2015) refers to a number of features enjoyed by Google educational applications. The most important of these features is that it provides the user with a storage capacity of about $15 \mathrm{~GB}$ and it provides a high level of protection in addition to it solve the problem of compatibility programs, The problem of losing documents through the use of cloud storage, and it works to create a kind of participation and communication between (learner and teacher) and also between learners with each other. 
Google Apps are one of the most important applications that can be used in web-based learning. These applications are provided free of charge by Google Inc. These include: Gmail, Google Sites, Google Docs, Google Calendar, Google Plus, and Google Talk (Taghreed Al-Rihili, 2013: 13).

Omar (2014: 325) believes that education in 2020 will focus on applications that are directly dependent on cloud methodologies such as hybrid classrooms, distance learning, and online education away from educational institutions. At this time Students or learners can create their own educational sites on the Internet, through which they can share and view files with their colleagues. Google Apps can be considered as an ideal solution that educational institutions can use to teach their students.

US state of Oregon has benefited from Google's educational services across its entire education sector, with an estimated number of 400,000 students. It has been reported that this initiative has provided about $\$ 1.5$ million Per year, in addition to motivating and preparing students to confront the real world.

In this context, a number of studies have pointed to the importance and effectiveness of the use of Google educational applications in the teaching process such as the Samanigo study (2010): which proved the effectiveness of Google's educational applications in the teaching of mathematics and the study of Al-Rahili (2013) Education on the achievement of students and the study of the names (2015): which proved the effectiveness of Google applications in increasing the achievement of students in the second grade secondary computer curriculum, and study Shammari (2014): Which proved the effectiveness of virtual classes in the Google Plus environment to increase the academic achievement of students relay Secondary computer course.

It is possible to say that by using Google educational applications in the teaching of computer curriculum, it will help to increase students' academic achievement, as these applications help students and teachers to reduce the effort and save time and it does not comply with a particular place, and no time, where possible Access to these applications anytime, anywhere, and this will help to provide a good and attractive learning environment that will be easy and loving to the students.

\section{Chapter one: Definition of Research:}

\section{First: - Research's problem:}

The computer lesson is a difficult which has developed significantly in our time and increased interest in it, and by looking at the computer as a subject taught in the colleges of education in Iraq, it is considered courses that students find difficult to understand and deal with it and most of the teachers unfortunately use the method of the traditional lecture in teaching computer, and the number of hours of the practical side few because of the overcrowding of computer laboratories students, through the experience of the researcher in the field of teaching computer curriculum, they found it necessary to search for new strategies and applications used in teaching computer course and these applications that can be used in teaching computer course Google is educational applications (Google Apps for Education), which can be considered as a free bag, including multiple applications where the process of hosting these applications on the Internet in order to provide communication and cooperation between the teachers with each other and between the teachers and their students, and learners, as these applications allow the professor to create a site of its own, Google Docs, which provides an opportunity for collaboration between learners and sharing information with each other very easily, so the researcher believes that the use of some Google educational applications in teaching computer curriculum will help to increase the educational achievement of students of the first year in the college of Education University of Samarra.

-The Google educational applications that will be used in this research are the following applications:
(Gmail):

(Google Docs):

Google (Google sites):

Google Social Network (Google +):

Google Calendar:

Second: The importance of the research:

1- This research helps to maintain communication between teachers and students at universities anywhere and anytime.

2- $\quad$ The results of this research help in the development of a number of proposals for the development of curricula for education in universities.

3- This research highlights new types of teaching methods that can be used in higher education.

4- This research helps to provide an effective and attractive teaching method that contributes to saving time and effort for both teaching and student.

5- $\quad$ The results of this research message to those concerned with the process of education in higher education needing to provide infrastructure suitable for the use of applications of (Cloud Computing), including the use of Google educational applications in teaching computer curriculum in particular and other courses in general.

\section{Third: Research's Aims:}

1- Objective limits: to identify the effect of the use of some Google educational applications in increasing the studying of students in the first year of the College of Education University of Samarra in computer curriculum.

2- $\quad$ Learn about the most important free applications for Google educational applications that can be used in the educational process.

Fourth: Research limits:

Objective limits: The current research has limited to use some free Google educational applications such as Gmail, Google Docs, Google sites, Google+, Google calendar. These applications will be used in a structured teaching method in college of Education/ University of Samarra. These topics are (computer components, electronic penetration, computer viruses, operating system). In the practical aspect, PowerPoint presentations were used as well as the use of instructional video in educational presentations related to the subjects of the computer course chosen for the purpose of teaching the sample.

Education.

Spatial limits: University of Samarra / College of (2016-2017).

Time Limits: The second semester of the academic year

Fourth: - Method of research: The researcher used the semiexperimental approach to suit the research objectives.

Fifth: Research hypotheses:

There were no significant differences at the level of significance $(0.05)$ between the mean scores of the experimental group and the mean scores of the control group students in the post-achievement test of the computer course.

\section{Sixth: - Terminology:}

\section{Google Apps for Education:}

- $\quad$ Thomas (2011: 214) defined it: is a collection of free tools provided by Google that are available on the Internet. These tools include Gmail, Docs, Which allows everyone to work on the same document at the same time to make the required corrections, and work to improve it in a distinctive and participatory manner.

- $\quad$ Known by Hussein, and Sumaidaie (2012: 148): It is a package of technical resources provided by Google free of charge. This package targets all educational institutions in order to improve the educational and educational outcomes. Google educational applications are among the most famous and important applications of cloud computing (Which can be used by educational institutions, whether schools or universities, to enhance communication and participation between teachers, students and learners in the educational community. This helps 
educational institutions to mobilize and focus their energies, time and budget in improving the process for educational purposes.

Procedural definition for Google Apps for Education is a free suite of applications that includes Google Apps, Google Docs, Google Sites, Google Calendar, and Google Groups. In the educational institutions such as schools, colleges and institutes, as these applications help the teacher to publish lectures for the course taught electronically through the use of multimedia (such as text, images, graphics, and video clips), these applications allow students to comment and then use Interactively, has been used These applications are integrated in the teaching of some topics of the computer curriculum in order to increase the academic achievement of the students of the first stage in the Department of Life Sciences at the college of Education, University of Samarra.

\section{Teaching:}

- $\quad$ Known by Attiyah (2009: 26): that all the possibilities, conditions and conditions provided by the teacher in a particular teaching position, in order to help students achieve the goals set for that position.

The definition of procedural teaching: is a continuous activity has been planned, and this activity aims to teach students of the Department of Life Sciences at the College of Education University of Samarra using some Google Apps for Education, in order to increase the academic achievement of students in the computer curriculum.

\section{Academic Achievement:}

- $\quad$ Recognition (Salah Addin, 2006, 20): Achievement is defined as "the degree of acquisition determined by the individual, the level of success achieved by him, or reaches him in a particular subject or field of education or training."

The researcher defines the procedure: The degrees obtained by students of the Department of biology at the College of Education University of Samarra in the post-achievement test prepared by the researcher in the computer curriculum.

\section{Chapter Two: The Theoretical Framework and the Previous Studies:}

First: The theoretical framework for Google educational applications: (Google Apps for Education):

1. Google Apps for Education:

- $\quad$ In August 2006, Google announced that it had launched a suite of free applications that are hosted on Google's servers without needing to install or download special software on its computer. Of (Google Apps for Education (GAFE)), with more than 50 million users in more than 190 countries (Google, 2016 / C), where more than 145) A country around the world Google educational applications officially in the educational institutions of their own, in addition to the survey has been about (15) million books It has been added to the Google Books site, and the previous figures show us that Google's free Google educational applications have become a key player in the development of education in educational institutions worldwide (Google In Education, 2012).

Bennett (2009: 9) points out that Google Education is a free service provided by Google that allows users to use custom domains with a large number of Google products that include Web-related applications and are very similar (E-mail, conversation, documents and calendar), which helps to exchange information, conduct a calendar process and conduct live conversations between users.

2. The most important Google educational applications used in the educational process:

\section{1. (Gmail):}

It is a free e-mail service offered by Google. The storage space is 15 gigabytes (GB) used for storing messages. Through this service, users can send and receive messages within their accounts immediately (Rouse, 2016).
Gmail is one of the most important e-mail servers, providing the user with large storage space, high availability, ease of handling, and good protection (Hassan, 2014: 13).

Nevin (2009: 35) points out that a user using Gmail uses cloud computing because a user can access his or her Gmail from anywhere in the world at any time, using any device Whether it is a computer or a mobile device, it is important that the device is connected to the Internet.

(Abboud, 2007: 189), and Miller (2008: 254) point to the most important features of Gmail:

1. Gmail helps you create virtual folders.

2. Gmail helps you sort messages and then sort them according to user needs.

3. Gmail provides users with a chat service that takes place between two or more people with voice and video.

4. Gmail helps a user distinguish between messages he has read and unread messages.

5. Gmail provides the user with the ability to save or reproduce the messages received to him in all its content.

6. Gmail allows you to add a sender's signature to the messages he or she sends.

7. Gmail helps a user save addresses from which messages are sent in organized and ordered lists.

8. Gmail will notify the user when new messages arrive, while busy with another program.

9. Gmail allows a user to attach text files, sounds, animated images, and static messages to their messages.

10. Gmail is protected by certain words and symbols that are not used by other users.

\section{2. (Google Docs):}

This service enables the user to write reports, memos or messages to friends or family. This service allows the possibility of creating, manipulating, editing and printing text files, and their participation through the Internet (Holzner, 2009).

In addition, this service allows the user to share, and allows the teacher to follow students in the application, where a number of students can be away from each other to make changes to a particular document and comment, and allows the comment feature in the editor (Google Docs) to identify the suspended person and time and date Comment, and this service keeps a copy of changes made to any file in the application (Adams, 2008: 99).

3. (Google sites):

It is a free service launched by Google on February 28, 2008, is used to build websites. This service enables educational institutions, businesses and students to create their own integrated websites without charge. The student or user can create their own website. This is a service that allows teachers and students to build their own websites for any purpose they want. It is possible that this is especially accessible only to teachers and students who have Google Accounts. In addition, these sites can share more than one user in the process of building them (Pitler, Hubbell, \& Kuhn, 2012).

There are advantages to Google sites that can be integrated with other applications of Google educational applications. For example, you can include documents, presentations or videos. Teaching can also benefit from Google sites by creating its own website or for the material he teaches at the university, and he can upload different files for his participation with his student (Open Education Center, 2012).

\section{Google Social Network (Google +):}

Google launched the social networking service (Google + ) on June 28, 2011, and specialists said that Google + is a challenge from Google for Facebook and Twitter. Google + has surpassed Twitter to rank The second largest social networking site after Facebook, and on (August 29, 2012) Google has added new features of the service (Google + ) and includes these new administrative tools to help reduce access to personal files and publications, November 5, 2013) Google has added a special security layer to restricted communities, allowing only this layer to be used inside the organization join it (Google Blog, 2013). 
Using social networking sites (Google+) in educational environments helps to greatly increase student learning by facilitating interaction between students and teachers and between students and their peers, making it easier for students to participate in the learning process (Ajjan \& Harsthon, 2008: 77).

The use of Google Social Networks (Google +): Helps increase student interaction with one another and their teachers on subjects such as subject matter, student group projects, student exams, and the learner community, all of which are heavily related to students comments and participation in social interaction (Balcikanli, 2012).

\section{Google Calendar:}

Google has designed the Google Calendar service on the Internet to work seamlessly with the Gmail application. The service was launched on (April 13, 2006), and Google Calendar is the most popular application on the Internet. It is linked to the most used search engine The Google Calendar is free and easy to use, and it is easy for the user to create shared or personal calendars. All events and calendar data are stored on the cloud and not on the user's computer. Thus, the calendar can be accessed from anywhere in the world and from any computer connected to the Internet. The calendar can be integrated quickly with the Gmail application, where Gmail can scan user's mail messages by dates and times. It is possible to create different types of calendars, such as personal calendars, Other users can access it through the Internet, and friends' calendars that can be imported from Google Calendar pages. (Miller, 2008: 91) and (al-Rahili, 2013: 48).

Adams (2008: 89) adds that Google Calendar provides users with the ability to send reminders that appear on the desktop of user computers or as text messages that reach users' mobile devices. This has an important role for parents Students who wish to follow the schedule of their children's classes, and also allow students and learners to organize their curricula and courses.

\section{6. (Google groups):}

It is a free service provided by Google. Users can create groups on the Internet and these groups are based on user email where users can create video calls (Hangouts), group's talking (Huddles), and engage in discussions on a particular topic (Group Help, 2016a).

\section{Features of Google Apps for Education:}

(Adams, 2008: 96), (Nevin, 2009: 35), (Samaniego, 2010), and (Sena , 2012) point to the most important features of Google's educational applications:

1. Google educational applications compatible with most mobile phones.

2. Google's educational applications have evolved into an important educational tool that can be used in the classroom.

3. Google educational applications do not consume the hard disk space of the computer.

4. Google Apps for Education provides automatic saving for any user action.

5. Google Education applications do not have to be on a user's computer to use.

6. When using Google educational applications less need to use the printer devices for easy access to these documents at any time and from anywhere.

7. Google Educational Apps offer large storage capacity for each user and for free.

8. Google's educational applications allow students and teachers to publish their documents as web pages, giving them the ability to make connections worldwide.

9. The requirements for using Google educational applications are the Internet browser installed on the device and then the ability to access the Internet.

10. Google educational applications facilitate the students and users of the process of publishing on the Internet without the user needs to learn programming languages.

11. Google educational applications allow students to learn about students' documents through their work on these documents. Therefore, the teacher can make corrective notes based on the documents created by the students. This gives the students opportunities to improve their work before handing over the meals they were assigned.

12. Google Apps for Education is a secure application that can not be accessed unless a person has his / her own account and password. These applications provide a high level of security for data and information.

13. Google educational applications provide a very important feature of teaching is the possibility of tracking the development of students, as these applications record every review by the student to the document, so the teaching is able to see all of these reviews and count the number, and if the work of students collectively and jointly on a specific document, The Google educational applications are the task of automatic registration of the person who completed the work and what the work done.

14. Google Apps educational applications free of charge is not for profit, it seeks to save and save a large amount of money for educational institutions, it provides for the educational sectors software as well as infrastructure crisis for the use of Google educational applications and thus contribute to redirect the money crisis of information technology to prepare And the rehabilitation of classrooms, which positively affects the improvement of the educational process.

15. Through the use of Google educational applications, it is possible to provide a virtual learning environment that helps to achieve communication and creativity not only at the level of students and learners, but for teachers who study the same courses, Google educational applications can be used in teaching different types of courses.

\section{Second: Previous Studies:}

1- The study of Al-Rahili (2013): The effect of using some Google educational applications in teaching the curriculum of educational techniques in educational achievement, social intelligence and the direction towards it among the students of Taibah University.

This study aimed to identify the effect of using some Google educational applications in teaching the curriculum of the techniques of education in the achievement of the academic and social intelligence of students of Taibah University. The study society may be from the students of college of Education at Taibah University for the academic year 2012-2013. The sample of the study consisted of (55) students from college of Education / Taibah University. The study sample was divided into two groups, one of which consisted of (25) students studied using Google educational applications through the use of integrated teaching method, 30) A student studied using the method of t The study used a number of statistical methods: arithmetic averages, standard deviations, Kronbach alpha, variance analysis, and (TTest) for independent samples. The study found the following results:

1. There are statistically significant differences at the level of $(0.05)$ between the mean scores of the experimental group and the control group in the post-achievement test at the level of (analysis, synthesis, and total evaluation) for the experimental group.

2- The study of Marwa Zaki (2012): The development of an electronic education system based on some applications of computer drawing to develop innovative thinking and the trend towards programs that work as services.

The aim of this study is to identify the effectiveness of an educational system based on some of the applications of computer drawing (Google drive) in order to develop innovative thinking and towards the programs that operate as free services. The study used the semi-experimental approach. The sample consisted of (60). The study was divided into two groups, one experimental and the other a control. The study tools were a test of innovative thinking related to the employment of e-learning, and a measure of the direction of students towards programs that work as free servers. To study the following statistical methods: Test (T-Test), and analysis of variance. In order to calculate the size of the effect was used the equation of (gay), and the results showed that there 
were statistically significant differences between the average scores of students of the experimental group and the control group students in the test of thought and the measure of direction Towards programs for the benefit of the experimental group, and recommended the study of the need to employ applications for computer drag in the educational process.

3. The study of (Herrick, 2009): Using Google for collaboration and productivity:

The aim of this study was to investigate the effect of the use of Google educational applications on the increase of cooperation and productivity. The descriptive approach was used in this study. This study was conducted at the University of Colorado in the United States of America. In 2009, The researcher explained the advantages of each of these applications, as well as put at the end of the study a financial comparison between the costs spent in the old system and the use of the use of Google educational applications, as the costs of the old system estimated B (\$9 million) while the use of Google Apps does not result in the disbursement of any funds The study recommended that the option to move to the use of Google educational applications is the best option, as the amounts of this option is ( 0 dollars), and the researcher That users of Google applications seemed to be satisfied with these applications especially the interoperability and versatility feature between applications which had a significant impact on increased collaborative productivity.

\section{Chapter Three: Research's Procedures}

\section{Experimental Design for Research:}

The design of the two groups (experimental and control) with the post-achievement test was chosen as an experimental design that the researcher deems appropriate to achieve the objectives of this research.

\section{2- Research community:}

All students of the first year in the Department of Biology at the College of Education at the University of Samarra for the academic year (2016-2017) were identified as (188) students to be the research community.

\section{3- Research Sample:}

The research sample was randomly selected from the research community. The research sample was 38 students, representing about $20 \%$ of the research community. They were divided into two equal groups in the number and two variables in the number of variables affecting the safety of experimental design of the experimental and control groups)

\section{4- Research requirements:}

- Determination of scientific material: The researcher identified four topics: (computer components, electronic penetration, computer viruses, operating system) from the computer curriculum book which is taught to students of the first stage in the Department of Life Sciences at the college of Education / University of Samarra during the second semester (2016 - 2017), so that these subjects chosen by the researcher is the scientific material of the current research.

- Determination of teaching aims: The researcher formulated the objectives related to teaching in the light of the general objectives of teaching the course of the computer, which was developed by the teaching staff assigned to teach the computer curriculum in the college of Education has been formulated in terms of specific teaching objectives, be measurable and the researcher presented to a group of Experts and specialists in order to demonstrate their validity, and finally have been definitively determined to be the intended objectives of teaching computer curriculum.

\section{Search Tools:}

-Web site: includes lectures and video clips for the computer course, as well as PowerPoint presentations for the computer course.

-Achievement Test:

The researcher prepared a final test of 50 questions, 25 of which are of the type of correctness and errors, and 25 of the multiple choice types. The test was conducted in a preliminary form by a group of experts (Cooper, 1974: 27). In order to conduct the statistical analysis of this test, it was applied to a survey sample consisting of $(80 \%), 19)$. The students were selected from a nonresearch sample. The researcher extracted the coefficient of discrimination and the coefficient of difficulty The correct substitutes for the test paragraphs were presented through the use of the appropriate statistical means which showed that the test paragraphs are distinctive and their difficulty is appropriate. The effectiveness of the wrong alternatives is good. Based on this, the test was considered honest to apply to the selected research sample.

\section{Application of the Research Experience:}

1- The researcher handed over the students of the experimental group (19) students, the guide on the use of Google educational applications.

2- $\quad$ The researcher trained the students of the experimental group on how to use some applications Google Education has been trained students through:

- Using the Data Show to help train the students in the experimental group to use some Google educational applications.

The students of the experimental group will train individually on some of the skills related to Google educational applications.

- $\quad$ Each student in the experimental group will create their own account on the Google search engine. If the student has his or her own Gmail, he or she will be free to use what he wants. The researcher will introduce students to how to send e-mails and how to deal with them. , And with different contacts, and thus each student of the experimental group has a special login name and password in order to maintain the confidentiality of its data.

The researcher identified the students of the experimental group with his e-mail address, as well as the students' e-mail addresses of their colleagues, so that it becomes a means of communication between the researcher and the students of the group.

- $\quad$ The researcher trained the students of the experimental group on how to create events through the use of Google Calendar, and determine the date of each event, and share with the rest of the group members.

- $\quad$ The researcher trained the students in the pilot group to work on Google + to add new members and allow them to work as a group so that they can have conversations and collective comments about the meals they are assigned.

The researcher provided link to the computer resources and give it to the students of the experimental group so that students can access the site and take advantage of the resources in it.

- The researcher recommended the students of the experimental group to direct any query on the subject at any time, whether during the training time or after.

After the completion of the teaching process, which lasted four weeks, the final test was applied to the students of the two groups (experimental and control). 


\section{7 - Statistical Methods: the Researcher Used A Number of Appropriate Statistical Methods, Including:}

Standard deviations.

Test (T-Test) for two independent samples.

\section{8- Search Results:}

Table (1) Results of the research

\begin{tabular}{|c|c|c|c|c|c|}
\hline Group & Sample size & Arithmetic mean & standard deviation & The degree of freedom & Calculated T value \\
\hline Control & 19 & 67.89 & 12.08 & \multirow{2}{*}{36} & \multirow{2}{*}{-3.71} \\
\hline Expermintal & 19 & 82.11 & 11.48 & & \\
\hline
\end{tabular}

\section{9 - Discuss the Results of the Research:}

The results of the study showed that there were statistically significant differences at the level of $(0.05)$ between the mean scores of the experimental group and the mean scores of the control group students in the final achievement test for the benefit of the experimental group. The use of these applications provided the experimental group with the ability to segment the scientific material that was prepared by the researcher at the site to its parts. These applications also provided students with a number of alternatives, such as sharing with colleagues in the scientific subject, Hand or through the use of all this conversation are easy on the experimental group students understand and comprehend the article on computer decision thus helped to increase the academic achievement of the students in the experimental group in the achievement

\section{Recommendations:}

1- $\quad$ The need to work to raise awareness of the parties involved in the educational process the role that can be done by Google's educational applications in the service of the educational process, and its impact on the increase in student achievement.

2- Work on the preparation of computers and Internet service in Iraqi universities in order to enable students to use Google's educational applications in the educational process and provide an appropriate learning environment.

3- Training students in universities and educational institutions on the use of Google educational applications in the educational process.

4- $\quad$ Adoption of the use of Google educational applications officially in universities and educational institutions in the teaching of computer curriculum in order to keep abreast of recent trends in the use of methods of e-learning and cloud computing technology.

5- Holding training courses and workshops for teachers in universities in order to train them on how to use Google's educational applications in the teaching process.

6- $\quad$ Focus on the development of plans and strategies for work in the field of e-learning in educational institutions and the expansion of the use of cloud computing technology in the teaching process.

\section{Proposals:}

To complement this research, the researcher suggests the following:

1- Research similar to the current research on the use of Google educational applications, and its impact on increasing the academic achievement of students in other courses and in different colleges.

2- Conduct similar research to the current research addresses the trends of teaching in universities and educational institutions towards the use of Google educational applications in the teaching process.
3- Conduct more research in order to identify the difficulties and constraints that limit the use of Google's educational applications in the teaching of the computer curriculum in universities and ways of treatment.

\section{References:}

[1] Hassan, Ahmed (2014): To learn about Google's features and services, Rabih Buhar journal, second year, p (14), Syria.

[2] Hussein, Laith, Sumaidaie, Abdullah (2012): Applications of General Cloud Computing in Organizations as a Proposed Model for Iraqi Educational Organizations, Rafidain Development, p. 110, vol. (34), pp. 141-156.

[3] Al-Rahili, Taghreed A. M. (2013): Effect of using some Google educational applications in teaching the curriculum of educational techniques in the achievement of academic and social intelligence and the direction towards it at the requests of the University of Taiba, unpublished $\mathrm{PhD}$ thesis, college of Education, Umm Al Qura University, Makkah

[4] Zaki, Marwa Tawfiq (2012): Development of an electronic learning system based on some applications of computer drawing to develop innovative thinking and the trend towards programs that serve as services, Journal of college of Education, 2 (147), 541-600, AlAzhar University, Egypt.

[5] Shammari, Abdul Karim (2014): Effect of teaching using virtual classes in the environment Google Plus on the achievement of the curriculum in the computer curriculum for students in the first grade secondary, King Saud University, Riyadh

[6] Saladin, Mahmoud, (2006): Educational and Psychological Measurement and Evaluation, Its Foundations, Applications and Contemporary Directions, Dar Al-Fikr Al-Arabi, Cairo.

[7] Aboud, H. Mahmoud (2007): Computer in Education, Hashemite Kingdom of Jordan, Amman, Dar Wael.

[8] Attia, Mohsen (2009): Modern Curriculum and Methods of Teaching, Dar Al-Maajah for Publishing and Distribution, Amman, Jordan.

[9] Omar, M. M. Mohammed (2014): The Role of Cloud Computing in Enhancing the Needs of a Society for Digital Arabic Knowledge, Journal of Literature (33), 303-332.

[10] Opened Education Center (2012): Advanced Skills Course in ELearning, Al-Quds Open University.

[11] http://etraining.qou.edu/

[12] Mustafa, Jamal (2015): Google Apps in Education, Journal of elearning was retrieved on 20/3/2017 at the link:

[13] http://emag.mans.edu.eg/index.php.page=news\&task=show\&id=10 7

[14] Al-Mousawi, Alaa (2008): Requirements for activating e-learning, a working paper presented to the first e-learning forum held at King Faisal Conference Hall at Intercontinental Hotel, Riyadh.

[15] Jesuliski, Brian (2010, July 19): Google Apps Used in Education, Translated by Isis Khalil, Retrieved on 1/5/2017 from the website:

[16] http //: cutt.us/aBKAd.

[17] Adams, D.C. (2008).Gaga For Google In The Twenty- First Century :Advanced Placement Language Classroom. The Clearing House, 82(2),Pp 96-100

[18] Ajjan, H.\& Harsthone, R(2008).Investigating Faculty Decisions To Adopt Web 2.0 Technologies :Theory And Empirical Tests. Internet And Higher Education.11,Pp80.

[19] Balcikanli,G.S.(2012).Social Networking In Physical Education:Undergrduate Students Views On Ning. Turkish On Line Journal Of Distance Education,13(2),Pp277-290

[20] Bennett,j.(2009).could computing: the future of internal comms? Strategic communication management, 14(1),p9. 
[21] Cooper, J. Measurement And Analysis Of Behavioral Techniques, Columbus, Chio, Charles ,E. Mcrill 1974.

[22] Google B $\log$ (2013).Private Conversations With Restricted Google+ Communities .Retrieved Online 14november 2014,From:"Private Conversations With Restricted Google + Communities".

[23] Google in education.(2012,1,1).Google Edu report full .retrieved from Google :http://goo.gl/ojkocb

[24] Group help.(2016a,4,23).Google Groups. Retrieved From Google Support:

[25] http://goo.gl/wo5fjQ

[26] Herrick ,D.R.(2009).Google This! Using Google For Collaboration And Productivity .fort Collins :Colorado state university

[27] Holzner, S.,\& Holzner, N,(2009). Google Docs 4 Everyone Lndianapolis, United States Of America: Bronkella Publishing

[28] Miller,M.(2008).Cloud Computing: Web -Based Applications That Change The Way You Work And Collaborate Online .USA ,New York ,Pearson.

[29] Nevin,R.(2009).Supporting 21 St Century Learning Through Google Apps.Teacher Librarian,37(2),Pp35-38.

[30] Pitler,H.,Hubbell,E.R.\&Kuhn,M.(2012).Using Technology With Classroom Instruction That Works. Colorado ,United States Of American :Mid -Continent Research For Education And Learning.

[31] Rouse ,M. $(2016,4,25)$.What Is Gmail? Retrieved From http://searchsoa .techtarget.com/http://goo.gl/DOBJFD

[32] Samaniego ,K.A.O.B.(2010) Google Your Math :Sustaining A Sociocultural Environment Though Collaborative Online Participation In Algebra. University If California .San Diego.

[33] Sena, T. (2012).Ultimate Guide To Gmail. Make Use Of Retrieved On Line 23 October 2016, From http://www.makeuseof.com/tag/ultimate - guide -gmail - pdf

[34] Thomas, P.Y.(2011),Cloud Computing :A Potential Paradigm For Practicing The Scholarship Of Teaching And Learning .Electronic Library,29(2) Pp. 214-224

[35] Yeung, k.(2012,10.01).this world teachers day Google celebrates educators who make a difference, retrieved from the next web :http//goo.gl/01oEYP. 